\title{
Decannulation Failure following Tracheostomy for COVID-19: A Single Case Report
}

\author{
Jake Causon ${ }^{1}$, Robyn Cary ${ }^{2}$ and Amanda Jane Thomas ${ }^{3 *}$ \\ ${ }^{1}$ Highly Specialist Physiotherapist, The Royal London Hospital, Barts Health NHS Trust, London, United Kingdom. \\ ${ }^{2}$ Highly Specialist Speech and Language Therapist, The Royal London Hospital, Barts Health NHS Trust, London, United Kingdom. \\ ${ }^{3}$ Clinical Specialist Physiotherapist, Critical Care Outreach Team, The Royal London Hospital, Barts Health NHS Trust, London, United Kingdom.
}

*Corresponding Author: Amanda Jane Thomas, Clinical Specialist Physiotherapist, Critical Care Outreach Team, The Royal London Hospital, Barts Health NHS Trust, UK.

Received date: June 14, 2021: Accepted date: August 24 2021: Published date: September 08, 2021

Citation: Jake Causon, Robyn Cary and Amanda Jane Thomas (2021) Decannulation Failure following Tracheostomy for COVID-19: A Single Case Report J. Clin Case Rep and Stu 2(6); DOI: 10.31579/2690-8808/082

Copyright: (c) 2021 Amanda James Thomas. This is an open access article distributed under the Creative Commons Attribution License, which permits unrestricted use, distribution, and reproduction in any medium, provided the original work is properly cited.

\begin{abstract}
The incidence, aetiology and long term outcomes of laryngotracheal complications secondary to Tracheostomy insertion in patients ventilated for COVID-19 critical Illness are currently unknown. We report a single case from our COVID-19 institutional series who developed early subglottic stenosis and subsequent traceomalacia preventing permanent tracheostomy removal despite three decannulation attempts. We consider the known risk factors for laryngotracheal complications following endotracheal intubation and tracheostomy, in combination with the potential impact of COVID-19 pathological features. Clinical indicators from the case presentation are explored in relation to the early identification of tracheomalacia in the patient with Tracheostomy, and the mechanisms underlying these presenting features are proposed.

Keywords: tracheostomy, decannulation, laryngeal stenosis, tracheomalacia
\end{abstract}

\section{List of Abbreviations}

OMFS: Oro-maxilla facial surgery; OWV: One way valve; FEES: Fibreoptic endoscopic evaluation of swallow; FNE: Fibreoptic nasendoscopy; CT: Computerised tomography; HFOT: High flow oxygen therapy; CPAP: Continuous positive airway pressure; HDU: High dependency unit; TM: Tracheomalacia; GORD: Gastrooesophageal reflux disease; OSA: Obstructive sleep apnoea, MDT: Multi-disciplinary team; SBT: Spontaneous breathing trial.

\section{Introduction}

The COVID-19 pandemic in the United Kingdom (UK) resulted in a large number of patients dependant on mechanical ventilation who subsequently required tracheostomy insertion. Outcomes of patients with tracheostomy following a COVID-19 diagnosis have thus far been concerned with reporting temporal characteristics such as time from insertion to decannulation and successful decannulation percentages [1, 2]. The incidence of tracheal complications and failure to decannulate in a COVID-19 cohort is currently unreported, although a small Italian sample reported a $47 \%$ incidence of full thickness tracheal lesions following Tracheostomy for COVID-19 related illness [3]. We report a single case from our institutional series who experienced more than one tracheal complication secondary to Tracheostomy insertion following COVID-19 critical illness and subsequently failed to decannulate over several attempts.

\section{Background}

Our patient was a 71 year old female admitted with a history of fever, cough and generalised weakness, on a background of type II diabetes, hypertension, hyperlipidaemia, cardiomyopathy, obstructive sleep apnoea (awaiting trial of home CPAP ), ischaemic stroke, and depression. COVID-19 pneumonitis and an acute kidney injury were diagnosed and the patient was transferred to the critical care unit.

Initial support via facemask CPAP was poorly tolerated resulting in respiratory arrest, cardiopulmonary resuscitation and emergency intubation (Grade 2b via bougie). Four days post intubation an endotracheal cuff leak required subsequent endotracheal tube change (Grade 2b). Supra-glottal instrumental assessment at this time identified bilateral oedematous arytenoids. Noticeable oedema of the lips and tongue were also observed which appeared to be exacerbated by prone positioning. Oro-maxilla facial surgical (OMFS) input recommended intra venous dexamethasone and chlorphenamine, but tongue swelling persisted. 
29 days after intubation, a surgical tracheostomy was inserted (size 7 TRACOE® twist plus, cuffed, non-fenestrated). During weaning from mechanical ventilation the patient was consistently able to tolerate cuff deflation but unable to tolerate placement of a one way valve (OWV) in line with the ventilator tubing. Once liberated from mechanical ventilation, intolerance to finger occlusion or OWV placement persisted.

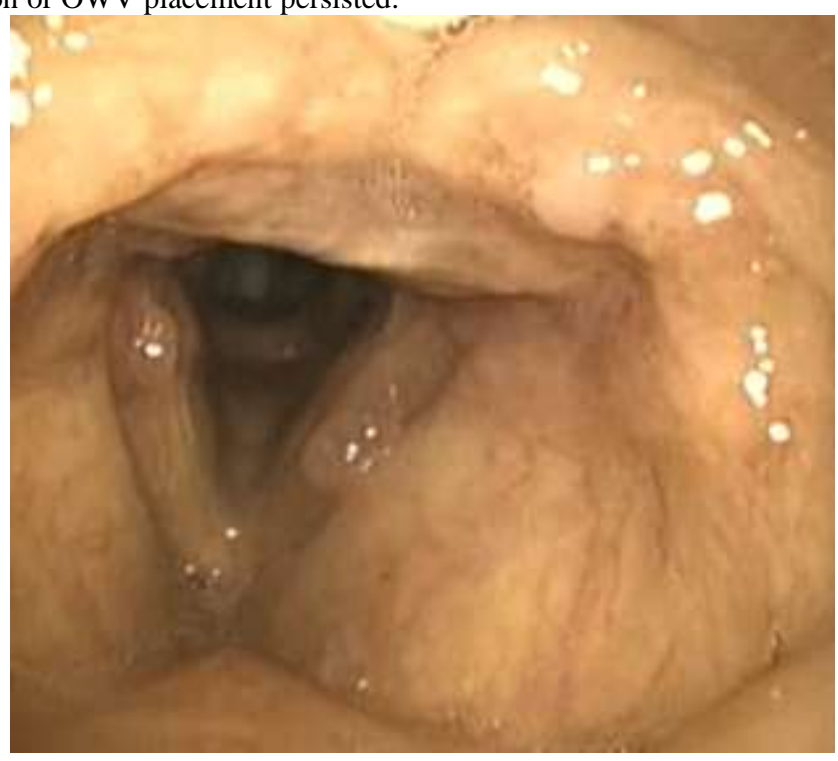

Figure 1. FEES image demonstrating patent supraglottis and subglottis (superior to the tracheostomy)

\section{Decannulation attempts}

30 days after the Tracheostomy was initially placed, the patient was decannulated but deteriorated over the next hour demonstrating increased work of breathing, anxiety and arterial desaturation to $70 \%$ with audible stridor. A size 6 TRACOE® twist cuffed, non-fenestrated tracheostomy tube was re-inserted over bougie into the existing stoma and specialist referral for airway investigation initiated. A third short course of dexamethasone was prescribed.

Following this first attempt, the patient was weaned to continuous cuff
A fibreoptic endoscopic evaluation of swallow (FEES) at this time revealed a patent supraglottic airway (Figure 1) and mild oro-pharangeal dysphagia, a short course of dexamethasone was prescribed for assumed airway oedema. The patient was subsequently able to tolerate the OWV all day and progressed to normal diet and fluids.

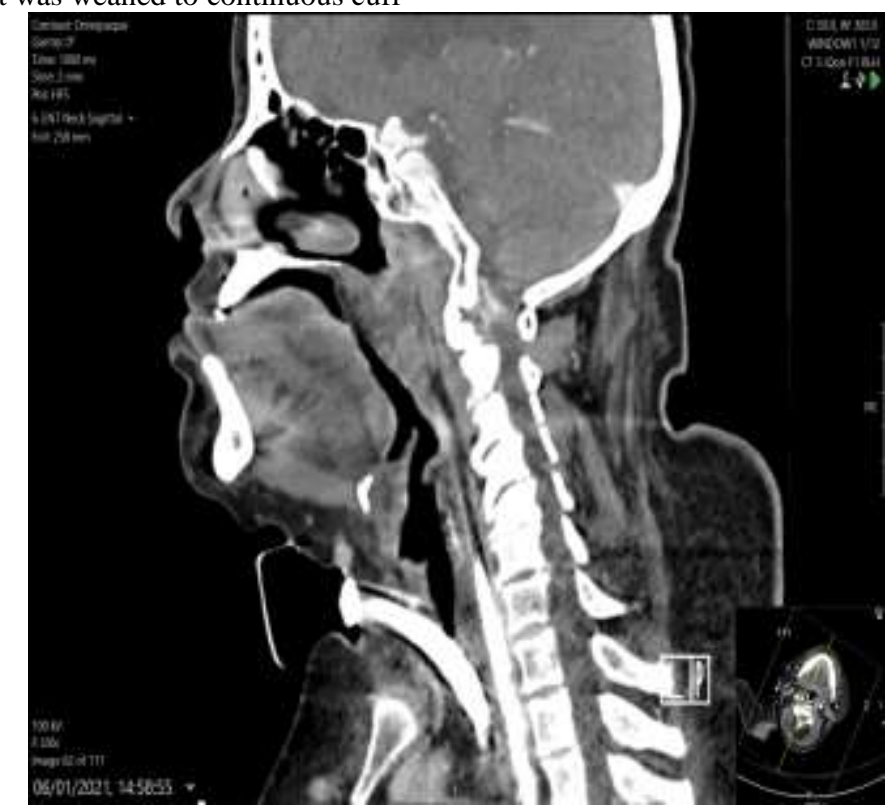

Figure 2. Contrast Computerised Tomography of the neck showing Tracheostomy tube and associated tracheal tissue changes above and below the point of insertion.

deflation but was consistently unable to tolerate the OWV demonstrating increased work of breathing and minimal airflow through the upper airway on digital tracheostomy occlusion. Fibreoptic Nasendoscopy (FNE) revealed a crowded oropharynx with prominent tonsils and base of tongue, normal vocal cord movement, glottic gap and minimal arytenoid oedema. A contrast CT neck (Figure 2) at this time demonstrated narrowing of the subglottic airway caudal to the tracheostomy site with a minimum cross-sectional diameter of $58 \mathrm{~mm}^{2}$ (compared to $168 \mathrm{~mm}^{2}$ at the same level in 2010). 
Micro-laryngoscopy revealed a $60 \%$ subglottic stenosis with anterior granulation proximal to the tracheostomy and a cartilaginous ring loose at the tracheostomy site. The subglottic stenosis was managed with tracheoplasty, laser ablation of the granulation tissue, cruciate cuts and balloon dilatation. Post-operatively, the patient was tolerant to cuff deflation but remained intolerant of OWV insertion. OWV intolerance was attributed to post-operative swelling and recurrent reduced subglottic patency, however repeat FNE on post-operative day 3 demonstrated a collapsing posterior tracheal wall on expiration.

Despite these findings a second decannulation attempt was made approximately 60 days following the initial tracheostomy insertion. The patient was stable initially, however the voice was noted to be significantly asthenic. Seven hours after decannulation the patient was stridulous with an increased work of breathing. FNE revealed a patent upper airway, however to avoid the risk of overnight deterioration a size 6.0 TRACOE® twist uncuffed, fenestrated tube was re-inserted into the existing stoma. Lansoprazole and dexamethasone were prescribed.

Following this second failed decannulation, trials of digital tracheostomy occlusion elicited a low pitch, rough strained vocal quality, immediate back pressure, cough, discomfort, desaturation and tachycardia. Several days later the patient experienced a respiratory arrest due to a plugging of the right main bronchus. FNE, microlaryngoscopy and bronchoscopy performed during and following the resuscitation event (and concomitant tracheostomy change) demonstrated a patent mid trachea to carina although mild malacea of the posterior trachea wall was noted. Proximally, the laryngeal appearances were normal although a haematoma on the right vocal cord was identified and a left vocal cord posterior polyp was removed with suction. Minimal granulation tissue and minimal stenosis of the sub-glottic area were reported.

Over the next few days the patient's respiratory function deteriorated requiring high flow oxygen therapy (HFOT) delivered via the Tracheostomy. Although continuous cuff deflation was well tolerated, placement of the OWV or digital tracheostomy occlusion resulted in immediate distress, increased work of breathing, and forceful coughing. Vocalisation attempts with the OWV in situ elicited a rough strained voice quality and short phrase speech. Application of the OWV in line with the HFOT appeared to increase valve tolerance but only to a maximum of 10mins. Repeat FNE revealed a clear view to the carina and main bronchi although mild malacia of the posterior tracheal wall was again noted.

In an effort to promote OWV tolerance a further tracheostomy change was performed (size 6 TRACOE® twist uncuffed non-fenestrated). Over the next 2 weeks tolerance to OWV (in line with the HFOT) progressed to greater than 4 continuous hours, although during these periods, the valve was repeatedly coughed off and replaced. Vocal trials remained dysphonic, strained and breathy, with short phrase speech. Interestingly, tolerance to OWV in the supine posture was limited (10secs) and associated with desaturation and increased work of breathing in comparison to OWV application in the upright posture which was consistently tolerated.

\begin{tabular}{|c|c|}
\hline $\begin{array}{l}\text { Patient related factors known } \\
\text { to increase risk [7] }\end{array}$ & Present in Case Report \\
\hline $\begin{array}{l}\text { Female and age (the risk of } \\
\text { vocal cord paralysis is } \\
\text { increased three-fold } \\
\text { in patients aged }>50 \mathrm{yrs} \text { ) }\end{array}$ & $\begin{array}{l}\text { Female } \\
72 \text { yrs old }\end{array}$ \\
\hline Obesity & $\begin{array}{l}\text { Obesity (including pre-existing } \\
\text { severe Obstructive Sleep Apnoea) }\end{array}$ \\
\hline $\begin{array}{l}\text { Gastro Oesophageal Reflux } \\
\text { Disease (GORD) }\end{array}$ & Gastro Oesophageal Reflux Disease \\
\hline
\end{tabular}

\begin{tabular}{|l|l|}
$\begin{array}{l}\text { Tube and other related factors } \\
\text { known to increase risk [7] }\end{array}$ & Present in case report \\
$\begin{array}{l}\text { Intubation (increased risk if } \\
\text { emergency intubation over elective). }\end{array}$ & $\begin{array}{l}\text { Initial emergency intubation for } \\
\text { hypoxic arrest. }\end{array}$ \\
\hline $\begin{array}{l}\text { Prolonged intubation with tube } \\
\text { changes }\end{array}$ & $\begin{array}{l}\text { Intubated for 29 days with 1 } \\
\text { endotracheal tube change including } \\
\text { tracheostomy insertion with } 6 \\
\text { tracheostomy changes }\end{array}$ \\
\hline $\begin{array}{l}\text { The skill level and experience of the } \\
\text { operator }\end{array}$ & $\begin{array}{l}\text { Unknown skill level and experience of } \\
\text { the operator }\end{array}$ \\
\hline
\end{tabular}

In preparation for a third decannulation attempt the patient was weaned to cold humidification and subject to a capping trial. Capping was poorly tolerated with immediate increased work of breathing and intolerance. Facial CPAP (CPAP-Vivo -Breas $\left.{ }^{\circledR}\right)$ with incremental pressures to $10 \mathrm{cmH}_{2} \mathrm{O}$ were trialled in an attempt to splint the airway during further capping attempts. Although the patient was tolerant of facial CPAP, simultaneous use with the tracheostomy cap did not improve tolerance.

The third decannulation was planned with the agreement of the multiprofessional team, 29 days after the second failed attempt. To ensure appropriate safety netting in the event of poor outcome, the patient was transferred to the high dependency unit (HDU) for the procedure. FNE immediately prior to the procedure demonstrated glottic opening and a distant view of the sub-glottis above the tracheostomy revealed no stenosis. Upon decannulation, the patient immediately desaturated, became bradycardic and visibly distressed with notable inspiratory retraction of the stoma site. A trial of facial CPAP failed to alleviate these features, and a size 6 TRACOE® twist cuffed non-fenestrated tube with subglottic port was reinserted. Three days later, some 90 days following initial tracheostomy insertion, the tube was changed (Size 6 TRACOE® twist un-cuffed fenestrated), and discharge planning for long-term Tracheostomy was initiated.

\section{Discussion}

In the case presented, an early $60 \%$ sub-glottic tracheal stenosis identified on micro-laryngoscopy prevented Tracheostomy removal. Since the patient was unable to tolerate placement of a one way valve (which directs expiratory airflow through the glottis) "in line" with the ventilator [4], this stenosis may have been present at a very early stage. Laryngeal stenosis has been reported to occur in $2 \%$ of patients whose trachea is intubated for 2-5 days, and 5\% when intubation is between 6 and 10 days [5]. Results of surgical intervention for stenosis is usually good, although two thirds of patients with iatrogenic stenosis may eventually require long term tracheostomy [6].

It is well understood that prolonged tracheal intubation or subsequent tracheostomy may damage or impair the larynx in a non-COVID-19 population. Wallace and McGrath, 2021 [7] classify laryngeal complications after tracheal intubation and tracheostomy, as early (including laryngeal oedema, vocal cord palsy or paresis); late (including anterior glottic web, arytenoid cartilaginous trauma); and very late (including glottic and subglottic stenosis) events. While there is limited data exploring the aetiology, type and extent of laryngeal injury following intubation, there are known risk factors that appear to influence complication incidence. Some patient characteristics are thought to adversely affect tissue perfusion and healing, or predisposition to neuropathy. Other risk factors are associated with physical interventions such as intubation, tracheal tube type and patient positioning [7]. In Table 1 we compare the known risk factors for laryngotracheal complications (post intubation or tracheostomy) with our case, and suggest that these features may have predisposed complications without the additional contribution of COVID-19 illness. 


\begin{tabular}{|l|l|l|l|}
\hline Renal or hepatic failure & $\begin{array}{l}\text { Acute kidney injury requiring } \\
\text { continuous filtration }\end{array}$ & $\begin{array}{l}\text { Use of a bougie or introducer and } \\
\text { the coinsertion of a gastric tube }\end{array}$ & $\begin{array}{l}\text { Grade 2B intubation with use of } \\
\text { bougie }\end{array}$ \\
\hline Diabetes mellitus & Diabetes mellitus & $\begin{array}{l}\text { Size of the tracheal tube } \\
\text { used (diameter or the patient } \\
\text { height/tracheal tube diameter } \\
\text { ratio) and design of the tube and } \\
\text { cuff. }\end{array}$ & Unknown \\
\hline Hypertension & Hypertension & $\begin{array}{l}\text { High mean cuff pressure and } \\
\text { volume }\end{array}$ & Unknown \\
\hline Malnutrition & $\begin{array}{l}\text { Likely malnourished due to } \\
\text { extended critical care stay }\end{array}$ & $\begin{array}{l}\text { Prone positioned for } 6 \text { days during the } \\
\text { period of mechanical ventilation }\end{array}$ \\
\hline Prolonged critical illness & $\begin{array}{l}\text { Prolonged critical illness including } \\
\text { critical care acquired weakness }\end{array}$ & Inadequate humidification & Unknown \\
\hline High dose Corticosteroids & $\begin{array}{l}\text { Prolonged and repeated use of } \\
\text { corticosteroids during critical care } \\
\text { stay }\end{array}$ & $\begin{array}{l}\text { Psychological factors including } \\
\text { agitation (whilst intubated) }\end{array}$ & $\begin{array}{l}\text { Agitated whilst intubated, anxious, } \\
\text { depressed, reduced motivation, } \\
\text { separation from family, possible PTSD }\end{array}$ \\
\hline $\begin{array}{l}\text { Induction of anaesthesia } \\
\text { utilising propofol and } \\
\text { midazolam }\end{array}$ & $\begin{array}{l}\text { Induction of anaesthesia utilising } \\
\text { propofol and midazolam and } \\
\text { fentanyl }\end{array}$ & & \\
\hline
\end{tabular}

Table 1: Comparison of published risk factors [7] for tracheal complications post endotracheal intubation or Tracheostomy with features in this case presentation

To our knowledge, the incidence of laryngotracheal complications and failure to decannulate in a COVID-19 cohort is currently unreported. Fiacchini et al, 2020 [3] report $46.7 \%$ of their COVID -19 cohort developed full thickness tracheal lesions and or trachea-oesophageal fistulas after invasive ventilation compared to $1 \%$ in matched nonCOVID-19 controls. These authors propose several causative mechanisms relating to COVID-19 treatments and pathophysiology, for example the use of prone positioning that may increase pressure on the tracheal wall and exacerbate tracheal necrosis; the pro-thrombotic and anti-fibrinolytic state of patients with COVID- 19 which predisposes micro vascular injury; and corticosteroid use resulting in mucosal atrophy and delayed healing [8].

Although tracheoplasty to manage subglottic stenosis in our case was successful, the patient was unable to be decannulated. Repeated inability to decannulate from tracheostomy in this case was attributed to a diagnosis of Tracheomalacia (TM), which has been defined as diffuse or segmental tracheal weakness due to the softening of the tracheal cartilage. Tracheobronchomalacia exists when this weakness extends into one or both of the main stem bronchi. Both conditions cause narrowing of the airway during expiration $[9,10]$.

Although TM can be congenital [10], endotracheal intubation or tracheostomy can elicit an acquired cause. These tubes can damage the tracheal cartilage or membrane at the level of the cuff or stoma site weakening the tracheal wall. Acquired TM is usually segmental and associated with prolonged intubation, concurrent high dose steroids and cuff pressures in excess of $25 \mathrm{cmH}_{2} \mathrm{O}$ [11]. The mechanism eliciting these features is uncertain but may include pressure necrosis, impaired blood flow, recurrent infection, mucosal friction and mucosal inflammation. Early COVID-19 research [3] suggests the virus itself may increase the incidence of micro vascular injury and necrosis of the tracheal mucosa. The prevalence of TM in the COVID-19 Tracheostomy cohort may be further increased through high viral replication in the tracheal epithelium [3].

The prevalence of TM in adults post translaryngeal intubation or tracheostomy is currently unknown. Kandaswarmy et al, 2013 [12] report severe TM (complete tracheal collapse on expiration when PEEP is removed) in $22 \%$ of patients who failed extubation after a successful spontaneous breathing trial (SBT). The prevalence of GORD (gastrooesophageal reflux disorders), prolonged critical care stay and obesity was higher in the severe TM group compared to matched controls, suggesting these features may increase risk. Similar risk factors for TM have been reported [13] and the effect of tracheal mucosa exposure to digestive enzymes on tensile tracheal strength has been previously postulated [14]. Potential risk factors for the development of Tracheomalacia in our case are listed in Table 1, including features of the critical care stay which may have exacerbated the problem. Of interest, Kandaswarmy et al, 2013 [12] suggests that pre-existing TM in the critical care setting can be misdiagnosed as obstructive sleep apnoea (OSA), and may exist with a higher incidence than expected, particularly since endotracheal intubation and ventilation delay the early recognition of substantial tracheal collapse. Our case had a diagnosis of OSA prior to admission and was waiting assessment for CPAP, raising the possibility that TM existed pre-morbidly and progressed secondary to events post admission.

Subtle features of the clinical presentation may have alerted the multidisciplinary team (MDT) to the potential for TM to limit decannulation from Tracheostomy. For example, the patient was never consistently able to tolerate a OWV with comfort, despite the fact that after resolution of the initial subglottic stenosis, the glottic and supraglottic structures were consistently reported as normal or near normal on FNE. Application of the OWV is known to increase subglottic tracheal pressure [15] due to restoration of expiratory glottic flow; however the increases in expiratory dead space, flow rate and pressure change elicited by the OWV may exacerbate both inspiratory and expiratory tracheal diameter changes when the trachea itself lacks structural integrity.

Tolerance to the OWV was improved with the application of HFOT via the Tracheostomy, which may generate an increase in dynamic positive pressure within the trachea limiting both inspiratory and expiratory tracheal collapse. Tolerance to the OWV was also improved in the upright compared to the supine posture where chest wall and abdominal resistive loads may have widened the dynamic tracheal pressure change exacerbating tracheal collapse. Despite patency of the upper airway, the patient was unable to tolerate Tracheostomy capping, suggesting that increasing both inspiratory and expiratory dead space and the associated increase in tracheal pressure changes exacerbated intolerable dynamic tracheal collapse. We presume that the Tracheostomy tube itself was acting as a "splint" within an airway with variable integrity [16], which when removed elicited symptomatic dynamic tracheal collapse. 
The extent to which morbidity related to both COVID-19 and a prolonged critical care stay influenced the presenting features in this case are difficult to differentiate. Extreme breathlessness on exertion, critical care acquired weakness, radiological evidence of lung fibrosis, post-traumatic stress disorder (PTSD), high level anxiety and poor motivation have been frequently reported consequences in critical care survivors following a COVID-19 admission. In addition, failure to decannulate over several attempts may have increased patient anxiety and overall engagement with the weaning process. These physical and psychological factors are likely to have prolonged the process of achieving the potential for decannulation and therefore cannot be excluded from a causative discussion.

\section{Conclusion}

Our case was unable to be decannulated from Tracheostomy following a prolonged critical care stay elicited by COVID-19 pneumonitis. The patient initially developed a subglottic stenosis which was surgically managed but failed to enable the tracheostomy to be removed. Further decannulation attempts, select investigations and interpretation of the clinical presentation resulted in a diagnosis of Tracheomalacia and long term Tracheostomy. The long term outcomes and prevalence of tracheal complications in patients ventilated and tracheostomised for COVID-19 are currently unknown. On-going review and surveillance of this cohort may allow the early identification and management of morbidity and a greater understanding of complication prevalence.

\section{Reference}

1. Tornari, C., Surda, P., Takhar, A., Amin, N., Dinham, A., et al. (2021). Tracheostomy, ventilator wean and decanulation in COVID-19 patients. European Archives of Oto-RhinoLaryngology; 278: p1595-1604.

2. Martin-Villares, C., Molina-Ramirez, C.P., Bartolome-Benito, M., and Bernal-Sprekelsen, M. (2020) Outcome of 1890 tracheostomies for critical COVID-19 patients: a national cohort study in Spain. European Archives of Oto-Rhino-Laryngology.

3. Fiacchini, G., Trico, D., Ribechini, A., Forfori, F., Brogi, E., et al. (2020) Evaluation of the incidence and potential mechanism of tracheal complications in patients with COVID-19. JAMA Otolaryngol Head Neck Surg, 147(1), p70-76.
4. Sutt A-L., Fraser, J (2015) Speaking valves as standard care with tracheostomised mechanically ventilated patients in intensive care unit. J Crit Care. 30; p1119-20.

5. Mota, L., de Cavalho, G., and Brito, V. (2012) Laryngeal complications by orotracheal intubation: literature review. Int Arch Oto-rhinolaryngol; 16: p236-45.

6. Gelbard, A., Francis, D.O., Sandulache, V.C., Simmons, J.C., Donovan, D.T., and Ongkasuwan, J. (2014). Causes and consequences of adult laryngotracheal stenosis. Laryngoscope: 125: $\mathrm{p}$ 1137-43.

7. Wallace, S., and McGrath, B.A. (2021). Laryngeal complications after tracheal intubation and tracheostomy. BJA Education.

8. Rhen, T., and Cidlowski, J.A. (2005) Anti-inflammatory action of glucocorticoids-new mechanisms for old drugs. $N$ England $J$ of Medicine. 353(16); 1711-1723.

9. Carden, K.A., Boiselle, P.M., Walyz, D.A., and Ernst, A. (2005) Tracheomalacia and tracheobroncomalacia in children and adults: an in-depth review, Chest; 127, p984.

10. Buitrago, D.H., Wilson, J.L., Parikh, M., Majid, A. and Gangadharan, S.P. (2017). Current concepts in severe adult tracheobronchomalacia: evaluation and treatment. Journal of Thoracic Disease; 9(1), E57-E66.

11. Ferguson, G.T., Benoist, J., (1993) Nasal continuous positive airway pressure in the treatment of tracheobronchomalacia. American review of Respiratory Disease. 147; p 457.

12. Kandaswamy, C., Bird, G., Gill, N., Math, E and Vempilly, J.J. (2013) Severe Tracheomalacia in the ICU: Identification of Diagnositic criteria and risk factor analysis from a case control study. Respiraory Care, 58(2), p340 - 347.

13. Vorakunthada, Y. and Lilitwat, W. (2018) Post-intubation tracheobronchomalacia in a young adult: A rare case report. Respiratory Medicine Care Reports, 23, p 66-67.

14. Greenfield, I.J., Singleton, D.R., MCCaffree, D.R. and Coalson, J.J. (1969), Pulmonary effects of experimental graded aspiration og hydrochloric acid. Ann. Surg. 170 (1); p74-86.

15. Sutt AL, Caruana LR, Dunster KR, Cornwell PL, Anstey CM, Fraser JF. (2016) Speaking valves in tracheostomised ICU patients weaning off mechanical ventilation - do they facilitate lung recruitment. Critical Care; 20: 1-9.

16. Mayilvaganan, S., and Agarawal, A (2014). Management of post thyroidectomy tracheomalacia. World J Endo Surg. 6: p96-98.

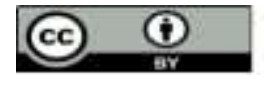

This work is licensed under Creative Commons Attribution 4.0 License

To Submit Your Article Click Here: Submit Manuscript

DOI: $10.31579 / 2690-8808 / 082$

\author{
Ready to submit your research? Choose Auctores and benefit from: \\ * fast, convenient online submission \\ * rigorous peer review by experienced research in your field \\ * rapid publication on acceptance \\ * authors retain copyrights \\ * unique DOI for all articles \\ * immediate, unrestricted online access
}

At Auctores, research is always in progress.

Learn more www.auctoresonline.org/journals/journal-of-clinical-casereports-and-studies 